\title{
A potential role for astaxanthin in the treatment of bone diseases (Review)
}

\author{
MARIA TERESA VALENTI ${ }^{1}$, MASSIMILIANO PERDUCA ${ }^{2}$, MARIA GRAZIA ROMANELLI ${ }^{3}$, \\ MONICA MOTTES $^{3}$ and LUCA DALLE CARBONARE ${ }^{1}$ \\ Departments of ${ }^{1}$ Medicine, ${ }^{2}$ Biotechnology and ${ }^{3}$ Neurosciences, \\ Biomedicine and Movement Sciences, University of Verona, 37100 Verona, Italy
}

Received December 2, 2019; Accepted June 5, 2020

DOI: $10.3892 / \mathrm{mmr} .2020 .11284$

\begin{abstract}
Alterations in molecular signaling impair cellular functions and induce degenerative diseases. Among the factors affecting intracellular signaling pathways, oxidative stress serves an important role. Astaxanthin (3,3'-dihydroxy- $\beta$, $\beta$-carotene-4,4'-dione), a pigment found in aquatic organisms, belongs to the xanthophylls family. Astaxanthin exerts a strong antioxidant activity and is widely used in food, cosmetic and pharmaceutical industries. Oxidative stress damages bone homeostasis by producing reactive oxygen species and increasing the production of pro-resorption cytokines, such as interleukin (IL)-1, tumor necrosis factor- $\alpha$ and IL-6. Therefore, antioxidant molecules can counteract the negative effects of oxidative stress on bone. Accordingly, previous studies have demonstrated that supplementation of astaxanthin in bone contributes to the restoration of bone homeostasis. The present review summarizes the negative effects of oxidative stress in bone and explores the role of astaxanthin in counteracting skeletal injuries consequent to oxidative stress.
\end{abstract}

\section{Contents}

1. Introduction

2. Skeletal degenerative diseases associated with oxidative stress

3. Astaxanthin: Structure and properties

4. Delivery of astaxanthin

5. Role of astaxanthin in oxidative stress

6. Effects of astaxanthin on bone and cartilage

7. Conclusions

Correspondence to: Dr Maria Teresa Valenti, Department of Medicine, University of Verona, Ple Scuro 10, 37100 Verona, Italy E-mail: mariateresa.valenti@univr.it

Key words: oxidative stress, reactive oxygen species, bone remodeling, astaxanthin, antioxidant

\section{Introduction}

In the last few decades, the incidence of degenerative diseases, including neurodegenerative diseases, such as Alzheimer's disease, osteoporosis and osteoarthritis (OA) has increased in Western countries $(1,2)$ These common pathologies are caused by intrinsic and extrinsic factors, such as biological, environmental and lifestyle factors (3). In addition, an increase in life expectancy, as observed in France, United Kingdom, USA and Netherlands (4), has led to a higher incidence of degenerative diseases (5). Aging is often associated with degenerative diseases caused by molecular and cellular damages (6). Therefore, throughout ageing impaired molecular signaling and disrupted cellular processes induce loss of function in tissues with a consequent physical decline (7). Nutrients that increase longevity can counteract the detrimental consequences of ageing (8) For example, astaxanthin has been demonstrated to reduce oxidative stress and apoptosis in model organisms $(9,10)$, and thus can be considered an anti-aging antidote. This review highlights a possible role of astaxanthin in preventing or reducing the negative effects of degenerative diseases and, in particular, of pathologies related to the skeleton.

\section{Skeletal degenerative diseases associated with oxidative stress}

Oxidative stress and inflammation serve an important role in degenerative diseases. Reactive oxygen species (ROS) overproduction, resulting from oxidative stress, damages various biological molecules, including DNA, carbohydrates, proteins and lipids, causing alterations during cellular growth and differentiation processes, thus inducing apoptosis (7). Among degenerative diseases, bone diseases are associated with oxidative stress (11). The bone remodeling process, where old bone is replaced by newly formed bone, modulates redox state changes and increases ROS production. Defective antioxidant systems are also involved in the pathogenesis of bone loss (12). By inducing apoptosis in osteoblasts (cells with bone forming activity), ROS impair osteogenesis and mineralization. Increased osteoblastic apoptosis also promotes osteoclast-induced bone resorption, with oxidative stress further enhancing osteoclast differentiation $(11,13,14)$. 
In vitro experiments have demonstrated that $\mathrm{H}_{2} \mathrm{O}_{2}$ increases the number and activation of osteoclasts (15). In addition, as ROS are involved in the regulation of inflammation, ROS overproduction activates certain inflammatory factors such as tumor necrosis factor- $\alpha$ (TNF- $\alpha$ ) and lipopolysaccharide (LPS) (16). TNF- $\alpha$ is involved in bone homeostasis regulation by activating different cellular pathways such as the upregulation of DKK1 (17) or RANKL (18), the inhibition of matrix protein genes expression as well as the stimulation of expression of genes related in the osteoclastogenesis or by inducing the resistance to 1,25-dihydroxyvitamin D3 (1,25(OH)2D3) (19). Generally, TNF- $\alpha$ promotes bone resorption by stimulating osteoclastogenesis and reduces bone formation by inhibiting osteoblastogenesis (20).

Osteoclastogenesis and bone resorption are promoted by ROS under physiological and pathological conditions. In particular, ROS promote osteoclastogenesis by inducing receptor activator of nuclear factor- $\kappa \mathrm{B}$ (RANK) signaling $(21,22)$. Furthermore, oxidative stress affects fibronectin, an extracellular bone matrix component, by inducing its partial degradation, thereby impairing the proliferation and differentiation of osteoblasts (23). Oxidative stress involvement in the pathogenesis of osteoporosis has been investigated in several studies. For example, oxidative stress was demonstrated to increase bone resorption by inducing the expression of osteoclast-stimulating cytokines such as interleukin (IL)-1, TNF- $\alpha$ and IL-6 $(23,24)$. In addition, postmenopausal females were prone to oxidative stress damage due to reduced levels of $17 \beta$-estradiol (E2), a hormone with antioxidant activity (25).

TNF- $\alpha$ is associated with the pathogenesis of various inflammatory diseases such as rheumatoid arthritis and ankylosing spondylitis. Rheumatoid arthritis is characterized by inflammatory processes that impair cartilage and bone, through TNF- $\alpha$ and IL-1 (26). TNF- $\alpha$ production in rheumatoid arthritis promotes pro-inflammatory cytokines such as IL-1 and IL-17, thereby increasing osteoclast activity and promoting bone resorption (27). TNF- $\alpha$ also increases the production of matrix metalloproteinases (MMPs) and aggrecanases which degrade cartilage extracellular matrix (20). Ankylosing spondylitis is a chronic form of arthritis characterized by inflammation and impairment of new bone formation (28). In particular, in ankylosing spondylitis and spondyloarthritis disorders, bone resorption and bone formation processes occur simultaneously in proximal anatomical sites (29). Treatment of patients with TNF inhibitors reduces disease symptoms, albeit without recovering bone remodeling ability $(30,31)$.

\section{Astaxanthin: Structure and properties}

Astaxanthin (3,3'-dihydroxy- $\beta, \beta$-carotene-4,4'-dione) is a ketocarotenoid pigment belonging to the family of carotenoid oxygenated derivatives, known as xanthophylls (32). Astaxanthin is a red pigment commonly found in aquatic organisms such as shrimps, crabs and Salmonidae (33) and is produced primarily by microalgae and phytoplankton (34). Microalgae are at the base of the food chain and are ingested by zooplankton and crustaceans, which are the prey of certain fish (35). The pigment is absorbed by these organisms and can accumulate in their tissue (36), giving them a distinctive orange-pink color. Tetraterpene exerts a strong antioxidant activity and is widely used in food, cosmetic and pharmaceutical industries (32).

While most commercial astaxanthin, primarily manufactured and distributed by Roche Diagnostics, is obtained from chemical synthesis (37), the greater demand for natural foods and the high cost of synthetic production have stimulated research into the production of astaxanthin from microorganisms. Consequently, this alternative source is becoming more relevant in basic research and in industrial applications, resulting in new companies and startups focusing on natural astaxanthin production (38).

The microalgae Haematococcus pluvialis (36) and the yeast Xanthophyllomyces dendrorhous (39) are currently the most promising sources of natural astaxanthin production, making them model organisms for use in industry. Natural astaxanthin produced by $H$. pluvialis exhibits greater antioxidant activity when compared with synthetic preparation (40). However, the greater costs of algae growth, production and active molecule extraction substantially limits its distribution in the international market (41).

Astaxanthin is synthesized via the carotenoid pathway, beginning with $\beta$-carotene (42), which is derived from geranylgeranyl pyrophosphate synthesis. The central long chain formed by carbon atoms linked by conjugated double bonds, alongside the two terminal rings, are responsible for the chemical characteristics and light absorption properties of astaxanthin (Fig. 1). Astaxanthin, together with other carotenoids such as canthaxanthin, exhibits various antioxidant activities, serving roles as free radical scavengers and potent quenchers of ROS and reactive nitrogen species (RNS) (43). Astaxanthin possess antioxidant activity that is 100 and $\mathrm{x} 10$ greater than vitamin $\mathrm{E}$ and $\beta$-carotene, respectively (44). It is therefore known as a superantioxidant. Unlike other antioxidant molecules, astaxanthin is free of pro-oxidative effects and produces no toxicity at high dosages (45). In addition to its antioxidant activity, astaxanthin exerts anti-inflammatory effects by inhibiting the NF- $\kappa \mathrm{B}$ signaling pathway (46).

Natural astaxanthin may be associated with other compounds; for example, one or both hydroxyl groups may be esterified with different fatty acids (oleic, palmitic and stearic acid), forming a complex with proteins (carotenoproteins) or lipoproteins (carotenolipoproteins) (47) Natural astaxanthin produced in algae is always esterified, whereas its synthetic equivalent is not $(48,49)$.

Astaxanthin has a wide range of applications in food, animal feeding supplementation (50) aquaculture (51) nutraceutical (52) cosmetic (53) and pharmaceutical industries (54). Its antioxidant activity is exploited in medicine for the prevention of or as an adjuvant in various diseases such as cancer, dermatological disorders, inflammation and cardiovascular damage, as well as for the general enhancement of the immune response $(38,45)$.

\section{Delivery of astaxanthin}

Although astaxanthin possesses a strong anti-inflammatory activity (55), its use in nutraceuticals and in the medical-pharmaceutical field is limited. This is due to astaxanthin being highly unstable and easily degradable when heated. The presence of oxygen and light are therefore required for 


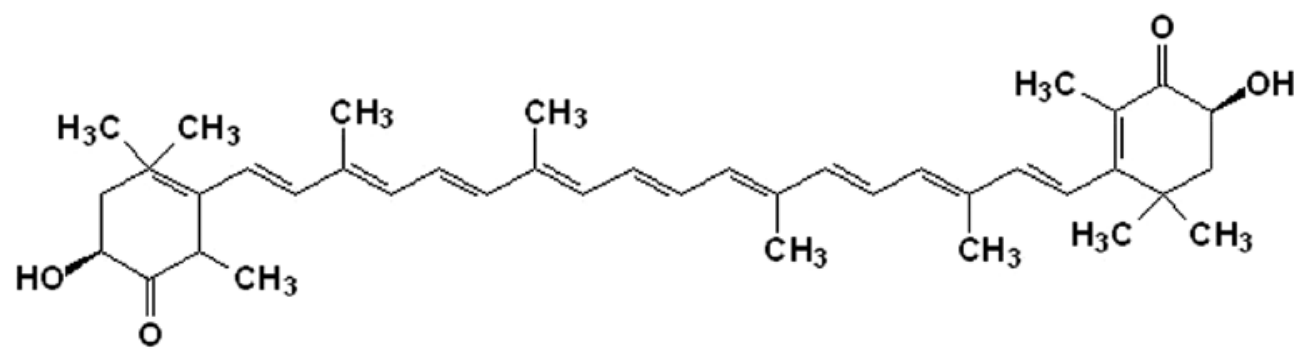

Figure 1. Chemical structure of astaxanthin.

its production, extraction and transformation, alongside additional technological processes such as mechanical and chemical treatments using solvents $(45,56)$. The chemical structure of astaxanthin makes it insoluble in water, which leads to difficulties in intestinal tract absorption if administered orally. The insolubility of astaxanthin also makes its parenteral administration difficult without solubilisers, such as DMSO (57); however, such solubilisers would change the chemical properties of the molecule (58).

The production of astaxanthin derivatives as prodrugs has been undertaken to overcome the aforementioned difficulties (45). An alternative approach is to encapsulate astaxanthin into particles with biocompatible and biodegradable polymers, conferring water solubility and a greater resistance to degradation; thus, specially designed micro- or nano- delivery structures, such as micro- and nano-dispersion systems, are under development $(59,60)$.

Astaxanthin formulation into nanostructures was initially employed to protect the active compound from thermal degradation and other physicochemical parameters such as $\mathrm{pH}$ and ionic strength $(56,61)$. Furthermore, this innovative approach has been used to improve yield during extraction from microorganisms (62-64) or to achieve a more sustainable production process (65). Another process conferring stability to the active molecule is its encapsulation into micro- and nano-alginate beads. This method is mainly used to entrap astaxanthin oil derivatives and produce a higher stability at room temperature over time, which is important for the shelf-life of nutraceuticals and food products $(66,67)$.

Since astaxanthin is mainly characterized by its low water solubility, novel approaches have been developed to enhance its bioavailability in cells using nanotechnology. The nanoencapsulation system most commonly used to study astaxanthin in an aqueous environment and for biomedical purposes is based on liposomes (68-70). The liposomal system preserves astaxanthin antioxidant activity as the nanoparticles used are non-toxic and cellular uptake is more efficient when compared with other delivery methods such as colloidal astaxanthin (71) or astaxanthin dissolved in dietary oils (72). Furthermore, astaxanthin can be coupled with other substances, such as vitamin E derivatives, to study their synergistic effects $(73,74)$.

Another polymer used to encapsulate astaxanthin is chitosan, a D-glucosamine polysaccharide obtained by digestion of the chitin shells of shrimps and other crustaceans with an alkaline agent (75) Chitosan encapsulated astaxanthin results in a non-toxic and biocompatible material with antibacterial activity, which confers stability and solubility in water, and increases bioavailability of the encapsulated active compound (76). This biopolymer can be used alone or in combination with other polymers, such as proteins. For example, the chitosan and $\beta$-lactoglobulin nanoparticle complex prolongs the release of astaxanthin and improves its stability when subjected to the extreme $\mathrm{pH}$ conditions of the gastrointestinal tract (77). Poly(lactic-co-glycolic acid) has been approved by the Food and Drug Administration and the European Medicines Agency together with chitosan for nanoparticle synthesis $(78,79)$. It is a biocompatible polymer that degrades into lactic and glycolic acid monomers, which enter into the Krebs cycle and are easily metabolized. The aforementioned polymers have been used recently to prepare astaxanthin loaded core-shell nanoparticles with good aggregation stability and increased bioavailability of the active compound when administered orally (60).

\section{Role of astaxanthin in oxidative stress}

Oxidative stress serves a central role in aging and in the development of various degenerative, neurodegenerative and inflammatory disorders, which are often the result of oxidative stress that affects mitochondrial function, disrupting cellular homeostasis (80).

Mitochondria regulate energy production at a cellular level and generate high levels of ROS. ROS produced by mitochondria are generally removed by superoxide dismutase, catalase and glutathione peroxidase (81). However, pathological disorders can induce an excessive production of mitochondrial ROS, the accumulation of which impairs mitochondria and consequently leads to cell damage (82). Damaged mitochondria exhibit morphological fragmentation. As the mitochondrial membrane potential is disrupted, their functionality is reduced. In addition, oxidative stress due to the accumulation of ROS, induces mitochondrial membrane permeabilization, leading to the activation of the intrinsic apoptotic pathway (83).

Astaxanthin scavenges singlet status oxygen molecules and free radicals, reducing lipid peroxidation (32). The ability to counteract excessive oxidation, thus causing lipidic alteration, is important in osteoporosis. It the authors' previous study, increased levels of modified lipoproteins derived from the oxidation of arachidonate-containing phospholipids (Ox-PAPCs) were identified in osteoporotic patient sera (84). In addition, it was demonstrated that Ox-PAPCs impair the osteogenic commitment of mesenchymal stem cells (MSCs) by downregulating Runt-related transcription factor 2 and upregulating adipogenic transcription factor peroxisome proliferator-activated receptor gamma 2 (84). 
Mutations and disrupted enzymatic activity occurring in mitochondria are often associated with atherosclerosis (85). In particular, damaged endothelial cells result from the overproduction of mitochondrial ROS in atherosclerosis (86). Antioxidants targeting mitochondria could prevent this dysfunction to protect endothelial cells (87). Previous studies have suggested that astaxanthin reduces oxidative stress affecting the mitochondria. For example, the role of astaxanthin in maintaining mitochondrial functions by modulating their redox state has been demonstrated (88). It was also revealed that astaxanthin maintained mitochondria in a reduced state in the presence of $\mathrm{H}_{2} \mathrm{O}_{2}$ (88). Supplementation of astaxanthin to increase ATP production and to potentiate the activity of the mitochondrial respiratory chain has been proposed to counteract age-associated diseases in dogs (89). Furthermore, astaxanthin can prevent cytochrome c release due to mitochondria permeabilization, consequently inhibiting apoptosis (81). As demonstrated in lung fibrosis, astaxanthin can prevent $\mathrm{H}_{2} \mathrm{O}_{2}$-induced apoptosis and bleomycin in alveolar epithelial cells (90). Pretreatment with astaxanthin in cardiotoxicity models has been demonstrated to prevent mitochondrial fragmentation, poly-ADP-ribose polymerase and caspase activity, thus inhibiting apoptosis (91).

ROS can impair redox balance in muscle after physical activity, inducing muscle fatigue and reducing exercise performance (92). Upon supplementation, astaxanthin accumulates in the liver, kidney and muscle, where it reduces DNA and lipid peroxidation, thereby preventing further muscle damage (93). It has been suggested that astaxanthin, by reducing the accumulation of exercise-induced ROS, can improve carnitine palmitoyl transferase 1 activity, increasing fat oxidation $(94,95)$. Astaxanthin has therefore been proposed for use in physical activity to counteract the negative effects of ROS production (96).

\section{Effects of astaxanthin on bone and cartilage}

Search strategy. Studies aiming to evaluate of the effects of astaxanthin on the skeletal system were collected from public databases. In particular, 80 full articles were identified by consulting the following databases: PubMed (https://pubmed. ncbi.nlm.nih.gov), Web of Science (http://login.webofknowledge.com) and Scopus (https://www.scopus.com) The search strategy employed in all databases was as follows: Astaxanthin AND bone/or mesenchymal cells/or osteoblasts/or skeletal/ or chondrocytes/or cartilage. Duplicates were removed and an independent screening of abstracts was performed for content consistency. A total of 9 papers were included.

Astaxanthin and bone. In chronic metabolic diseases, elevated levels of fatty acids impair the microenvironment of MSCs, affecting their viability and the production of certain cytokines, such IL-6, vascular endothelial growth factor and monocyte chemoattractant protein-1 (97). However, it has been demonstrated that astaxanthin supplementation protects MSCs from fatty acid induced-cell death and inflammatory effects (97). Antioxidant molecules can induce osteogenic differentiation and improve bone mineralization by counteracting oxidative stress $(12,98)$. Accordingly, it has been demonstrated that supplementation with astaxanthin in a model of periodontitis reduced osteoclast activity and increased osteoblast number in the mandible (99). It has been revealed that the supplementation of astaxanthin improved bone quality in ovariectomized mice, an in vivo model of osteoporosis (100). In particular, the authors observed reduced levels of bone resorption biomarkers, such as serum calcium, inorganic phosphorus, alkaline phosphatase and tartrate-resistant acid phosphatase (TRAP), and that bone mineral density and microarchitecture were recovered after 6 weeks of astaxanthin supplementation. In addition, by performing in vitro experiments, the authors observed that astaxanthin affected osteoclast activation by reducing the expression of nuclear factor of activated $\mathrm{T}$ cells $\mathrm{cl}$, dendritic cell-specific transmembrane protein, TRAP and cathepsin K (101). Furthermore, a recent study reported that in rats treated for 8 weeks with D-galactose $(200 \mathrm{mg} / \mathrm{kg})$, H. pluvialis biomass administration reduced bone loss (101). In particular, the authors observed that bone quality in treated rats improved via regulation of the osteoprotegerin (OPG)/RANKL pathway. This pathway regulates the crosstalk between osteoblasts and osteoclasts, consequently affecting the bone remodeling process (102). The aforementioned studies suggest the positive effects of astaxanthin in reducing bone loss. Its supplementation may therefore represent a useful tool for counteracting bone degenerative diseases.

Astaxanthin and cartilage. Previously published works have suggested positive effects of astaxanthin in OA experimental models. OA occurs due to chondrocyte dysfunction following an inflammatory state, with an overproduction of MMPs inducing the degeneration of articular cartilage (103). Two different studies have reported reduced expressions of MMP-1, MMP-3 and MMP-13 in the IL-1 $\beta$ stimulated chondrocytes of an in vitro experimental OA model treated with astaxanthin $(103,104)$. In particular, it has been demonstrated that astaxanthin prevented MMP production by reducing the phosphorylation of p38 and ERK1/2 activated by mitogen-activated protein kinase (104), or by downregulating the expression of $\mathrm{NF}-\kappa \mathrm{B}$ and activator protein-1, which are upstream regulators of MMP production (103). The administration of astaxanthin ameliorated cartilage status by reducing MMP production in an in vivo OA model obtained by damaging the knee anterior cruciate ligament in rabbits (105). Therefore, the supplementation of astaxanthin can be considered a beneficial treatment to counteract $\mathrm{OA}$.

\section{Conclusions}

Degenerative diseases and in particular bone diseases, cause physical disability and heavily impact public healthcare (106). Oxidative stress is considered an important cause of the pathogenesis of chronic and degenerative diseases. Therefore, targeted actions aimed at preventing or reducing the negative effects of oxidative stress are required. The use of natural antioxidant molecules, such as astaxanthin, may represent an effective strategy to counteract bone degenerative diseases.

To the best of our knowledge, few studies aiming to evaluate the use of astaxanthin in bone diseases have been performed thus far. The results of the present review may stimulate further investigations aimed at understanding and potentially supporting the use of astaxanthin against bone diseases. 


\section{Acknowledgements}

Not applicable.

\section{Funding}

No funding was received.

\section{Availability of data and materials}

Not applicable.

\section{Authors' contributions}

MTV, MP and MM conceptualized and designed the study. MTV, MP, MGR, MM and LDC acquired and interpreted the data, and wrote the manuscript. All the authors read and approved the final manuscript.

\section{Ethics approval and consent to participate}

Not applicable.

\section{Patient consent for publication}

Not applicable.

\section{Competing interests}

The authors declare that they have no competing interests.

\section{References}

1. Kopp W: How Western diet and lifestyle drive the pandemic of obesity and civilization diseases. Diabetes Metab Syndr Obes 12: 2221-2236, 2019

2. Badley EM and Davis AM: Meeting the challenge of the ageing of the population: Issues in access to specialist care for arthritis Best Pract Res Clin Rheumatol 26: 599-609, 2012.

3. Naylor RM, Baker DJ and van Deursen JM: Senescent cells: A novel therapeutic target for aging and age-related diseases. Clin Pharmacol Ther 93: 105-116, 2013.

4. Verstraeten SP, van Oers HA and Mackenbach JP: Differences in life expectancy between four Western countries and their Caribbean dependencies, 1980-2014. Eur J Public Health 30 85-92, 2020

5. Montero JA, Lorda-Diez CI and Hurlé JM: Regenerative medicine and connective tissues: Cartilage versus tendon. J Tissue Eng Regen Med 6: 337-347, 2012.

6. Escobar KA, Cole NH, Mermier CM and VanDusseldorp TA: Autophagy and aging: Maintaining the proteome through exercise and caloric restriction. Aging Cell 18: e12876, 2019.

7. Mohd Sahardi NF and Makpol S: Ginger (Zingiber officinale Roscoe) in the prevention of ageing and degenerative diseases: Review of current evidence. Evid Based Complement Alternat Med 2019: 5054395, 2019.

8. Sachdeva V, Roy A and Bharadvaja N: Current prospective of nutraceuticals: A review. Curr Pharm Biotechnol: Jan 29, 2020 (Epub ahead of print). doi: 10.2174/1389201021666200130113441.

9. Sj S, Veerabhadrappa B, Subramaniyan S and Dyavaiah M: Astaxanthin enhances the longevity of Saccharomyces cerevisiae by decreasing oxidative stress and apoptosis. FEMS Yeast Res: Jan 1, 2019 (Epub ahead of print). doi: 10.1093/femsyr/ foy113.

10. El-Baz FK, Hussein RA, Abdel Jaleel GA and Saleh DO: Astaxanthin-rich Haematococcus pluvialis Algal hepatic modulation in D-galactose-induced aging in rats: Role of Nrf2. Adv Pharm Bull 8: 523-528, 2018.
11. Tang X, Ma S, Li Y, Sun Y,Zhang K, Zhou Q and Yu R: Evaluate the activity of sodium butyrate to prevent osteoporosis in rats by promoting osteal GSK-3beta/Nrf2 signaling and mitochondrial function. J Agric Food Chem 68: 6588-6603, 2020.

12. Domazetovic V, Marcucci G, Iantomasi T, Brandi ML and Vincenzini MT: Oxidative stress in bone remodeling: Role of antioxidants. Clin Cases Miner Bone Metab 14: 209-216, 2017.

13. Chen X, Wang C, Qiu H, Yuan Y, Chen K, Cao Z, Xiang Tan R, Tickner J, Xu J and Zou J: Asperpyrone A attenuates RANKL-induced osteoclast formation through inhibiting NFATc1, $\mathrm{Ca}^{2+}$ signalling and oxidative stress. J Cell Mol Med 23: 8269-8279, 2019.

14. Prideaux M, Kitase Y, Kimble M, O'Connell TM and Bonewald LF: Taurine, an osteocyte metabolite, protects against oxidative stress-induced cell death and decreases inhibitors of the Wnt/ $\beta$-catenin signaling pathway. Bone 137: 115374, 2020.

15. Baek KH, Oh KW, Lee WY, Lee SS, Kim MK, Kwon HS, Rhee EJ, Han JH, Song KH, Cha BY, et al: Association of oxidative stress with postmenopausal osteoporosis and the effects of hydrogen peroxide on osteoclast formation in human bone marrow cell cultures. Calcif Tissue Int 87: 226-235, 2010.

16. Lingappan K: NF- $\mathrm{BB}$ in oxidative stress. Curr Opin Toxicol 7: 81-86, 2018

17. Li S, Yin Y, Yao L, Lin Z, Sun S, Zhang J and Li X: TNF- $\alpha$ treatment increases DKK1 protein levels in primary osteoblasts via upregulation of DKK1 mRNA levels and downregulation of miR-335-5p. Mol Med Rep: May 18, 2020 (Epub ahead of print). doi: $10.3892 / \mathrm{mmr} .2020 .11152$.

18. Marahleh A, Kitaura H, Ohori F, Kishikawa A, Ogawa S, Shen WR, Qi J, Noguchi T, Nara Y and Mizoguchi I: TNF- $\alpha$ directly enhances osteocyte RANKL expression and promotes osteoclast formation. Front Immunol 10: 2925, 2019.

19. Nanes MS: Tumor necrosis factor-alpha: Molecular and cellular mechanisms in skeletal pathology. Gene 321: 1-15, 2003.

20. Osta B, Benedetti G and Miossec P: Classical and paradoxical effects of TNF- $\alpha$ on bone homeostasis. Front Immunol 5: 48, 2014.

21. Ha H, Kwak HB, Lee SW, Jin HM, Kim HM, Kim HH and Lee ZH: Reactive oxygen species mediate RANK signaling in osteoclasts. Exp Cell Res 301: 119-127, 2004.

22. Lee NK, Choi YG, Baik JY, Han SY, Jeong DW, Bae YS, Kim N and Lee SY: A crucial role for reactive oxygen species in RANKL-induced osteoclast differentiation. Blood 106: 852-859, 2005.

23. Azizieh FY, Shehab D, Jarallah KA, Gupta R and Raghupathy R: Circulatory levels of RANKL, OPG, and oxidative stress markers in postmenopausal women with normal or low bone mineral density. Biomark Insights 14: 1177271919843825, 2019.

24. Azizieh F, Raghupathy R, Shehab D, Al-Jarallah K and Gupta R: Cytokine profiles in osteoporosis suggest a proresorptive bias. Menopause 24: 1057-1064, 2017.

25. Pansini F, Mollica G and Bergamini CM: Management of the menopausal disturbances and oxidative stress. Curr Pharm Des 11: 2063-2073, 2005

26. Gravallese EM, Harada Y, Wang JT, Gorn AH, Thornhill TS and Goldring SR: Identification of cell types responsible for bone resorption in rheumatoid arthritis and juvenile rheumatoid arthritis. Am J Pathol 152: 943-951, 1998.

27. Gravallese EM, Manning C, Tsay A, Naito A, Pan C, Amento E and Goldring SR: Synovial tissue in rheumatoid arthritis is a source of osteoclast differentiation factor. Arthritis Rheum 43: 250-258, 2000.

28. Carter S, Braem K and Lories RJ: The role of bone morphogenetic proteins in ankylosing spondylitis. Ther Adv Musculoskelet Dis 4: 293-299, 2012.

29. Hreggvidsdottir HS, Noordenbos T and Baeten DL: Inflammatory pathways in spondyloarthritis. Mol Immunol 57: 28-37, 2014.

30. Braun J and Sieper J: Ankylosing spondylitis. Lancet 369: 1379-1390, 2007

31. van der Heijde D, Salonen D, Weissman BN, Landewé R, Maksymowych WP, Kupper H, Ballal S, Gibson E and Wong R; Canadian (M03-606) study group; ATLAS study group: Assessment of radiographic progression in the spines of patients with ankylosing spondylitis treated with adalimumab for up to 2 years. Arthritis Res Ther 11: R127, 2009.

32. Yuan JP, Peng J, Yin K and Wang JH: Potential health-promoting effects of astaxanthin: A high-value carotenoid mostly from microalgae. Mol Nutr Food Res 55: 150-165, 2011

33. Milani A, Basirnejad M, Shahbazi S and Bolhassani A: Carotenoids: Biochemistry, pharmacology and treatment. Br J Pharmacol 174: 1290-1324, 2017. 
34. Novoveská L, Ross ME, Stanley MS, Pradelles R, Wasiolek V and Sassi JF: Microalgal carotenoids: A review of production, current markets, regulations, and future direction. Mar Drugs 17: 640, 2019.

35. Davies BH: Carotenoid metabolism in animals: A biochemist's view. Pure Appl Chem 57: 679-684, 1985.

36. Lorenz RT and Cysewski GR: Commercial potential for Haematococcus microalgae as a natural source of astaxanthin. Trends Biotechnol 18: 160-167, 2000.

37. Roche F: Astaxanthin as a Pigmenter in Salmon Feed, Color Additive Petition 7C02 1 1, United States Food and Drug Administration. In: Astaxanthin: Human Food Safety Summary. Hoffman-La Roche Ltd., Basel, p43, 1987.

38. Higuera-Ciapara I, Félix-Valenzuela L and Goycoolea FM: Astaxanthin: A review of its chemistry and applications. Crit Rev Food Sci Nutr 46: 185-196, 2006.

39. Kothari D, Lee JH, Chon JW, Seo KH and Kim SK: Improved astaxanthin production by Xanthophyllomyces dendrorhous SK984 with oak leaf extract and inorganic phosphate supplementation. Food Sci Biotechnol 28: 1171-1176, 2019.

40. Capelli B, Talbott S and Ding LX: Astaxanthin sources: Suitability for human health and nutrition. Funct Food Health Dis 9: 430-445, 2019.

41. McCoy M: Astaxanthin market a hard one to crack. Chem Eng News 77: 15-17, 1999.

42. Fraser PD, Miura Y and Misawa N: In vitro characterization of astaxanthin biosynthetic enzymes. J Biol Chem 272: 6128-6135, 1997.

43. Tanaka T, Shnimizu M and Moriwaki H: Cancer chemoprevention by carotenoids. Molecules 17: 3202-3242, 2012.

44. Kavitha K, Kowshik J, Kishore TKK, Baba AB and Nagini S: Astaxanthin inhibits $N F-\kappa B$ and $W n t / \beta$-catenin signaling pathways via inactivation of Erk/MAPK and PI3K/Akt to induce intrinsic apoptosis in a hamster model of oral cancer. Biochim Biophys Acta 1830: 4433-4444, 2013.

45. Satoh A, Tsuji S, Okada Y, Murakami N, Urami M, Nakagawa K, Ishikura M, Katagiri M, Koga Y and Shirasawa T: Preliminary clinical evaluation of toxicity and efficacy of a new astaxanthin-rich Haematococcus pluvialis extract. J Clin Biochem Nutr 44: 280-284, 2009

46. Bhuvaneswari S, Yogalakshmi B, Sreeja S and Anuradha CV: Astaxanthin reduces hepatic endoplasmic reticulum stress and nuclear factor- $\mathrm{\kappa} \mathrm{B}$-mediated inflammation in high fructose and high fat diet-fed mice. Cell Stress Chaperones 19: 183-191, 2014

47. Kidd P: Astaxanthin, cell membrane nutrient with diverse clinical benefits and anti-aging potential. Altern Med Rev 16: 355-364,2011

48. Johnson EA and An GH: Astaxanthin from microbial sources. Crit Rev Biotechnol 11: 297-326, 1991.

49. Yuan JP, Gong XD and Chen F: Separation and analysis of carotenoids and chlorophylls in Haematococcus lacustris by high-performance liquid chromatography photodiode array detection. J Agric Food Chem 45: 1952-1956, 1997.

50. Casella P, Iovine A, Mehariya S, Marino T, Musmarra D and Molino A: Smart method for carotenoids characterization in Haematococcus pluvialis red phase and evaluation of astaxanthin thermal stability. Antioxidants 9: 422, 2020.

51. Shah MM, Liang Y, Cheng JJ, Daroch M and Daroch $\mathrm{M}$ : Astaxanthin-producing green microalga Haematococcus pluvialis: From single cell to high value commercial products. Front Plant Sci 7: 531, 2016.

52. McCarty MF and Lerner A: Nutraceuticals targeting generation and oxidant activity of peroxynitrite may aid prevention and control of Parkinson's disease. Int J Mol Sci 21: 3624, 2020.

53. Alves A, Sousa E, Kijjoa A and Pinto M: Marine-derived compounds with potential use as cosmeceuticals and nutricosmetics. Molecules 25: 2536, 2020.

54. Menin B, Santabarbara S, Lami A, Musazzi S, Villafiorita Monteleone F and Casazza AP: Non-endogenous ketocarotenoid accumulation in engineered Synechocystis sp. PCC 6803. Physio Plant 166: 403-412, 2019.

55. Fakhri S, Abbaszadeh F, Dargahi L and Jorjani M: Astaxanthin: A mechanistic review on its biological activities and health benefits. Pharmacol Res 136: 1-20, 2018.

56. Tachaprutinun A, Udomsup $\mathrm{T}$, Luadthong $\mathrm{C}$ and Wanichwecharungruang S: Preventing the thermal degradation of astaxanthin through nanoencapsulation. Int J Pharm 374: 119-124, 2009.

57. Küçüködük A, Helvacioglu F, Haberal N, Dagdeviren A, Bacanli D, Yilmaz G and Akkoyun I: Antiproliferative and anti-apoptotic effect of astaxanthin in an oxygen-induced retinopathy mouse model. Can J Ophthalmol 54: 65-74, 2019.
58. Yuan JP and Chen F: Isomerization of trans-astaxanthin to cis-isomers in organic solvents. J Agric Food Chem 47: 3656-3660, 1999.

59. Hu Q, Hu S, Fleming E, Lee JY and Luo Y: Chitosan-caseinatedextran ternary complex nanoparticles for potential oral delivery of astaxanthin with significantly improved bioactivity. Int J Biol Macromol 151: 747-756, 2020.

60. Liu C, Zhang S, McClements DJ, Wang D and Xu Y: Design of astaxanthin-loaded core-shell nanoparticles consisting of chitosan oligosaccharides and poly (lactic-co-glycolic acid): Enhancement of water solubility, stability, and bioavailability. J Agric Food Chem 67: 5113-5121, 2019.

61. Tamjidi F, Shahedi M, Varshosaz J and Nasirpour A: Stability of astaxanthin-loaded nanostructured lipid carriers as affected by $\mathrm{pH}$, ionic strength, heat treatment, simulated gastric juice and freeze-thawing. J Food Sci Technol 54: 3132-3141, 2017.

62. Machado FR Jr, Trevisol TC, Boschetto DL, Burkert JF, Ferreira SR, Oliveira JV and Burkert CA: Technological process for cell disruption, extraction and encapsulation of astaxanthin from Haematococcus pluvialis. J Biotechnol 218: 108-114, 2016.

63. Bustamante A, Masson L, Velasco J, Del Valle JM and Robert P Microencapsulation of $H$. pluvialis oleoresins with different fatty acid composition: Kinetic stability of astaxanthin and alpha-tocopherol. Food Chem 190: 1013-1021, 2016.

64. Chen L, Wang JL, Ni H and Zhu MJ: Disruption of Phaffia rhodozyma cells and preparation of microencapsulated astaxanthin with high water solubility. Food Sci Biotechnol 28: $111-120,2018$.

65. Salatti-Dorado JA, García-Gómez D, Rodriguez-Ruiz V, Gueguen V, Pavon-Djavid G and Rubio S: Multifunctional green supramolecular solvents for cost-effective production of highly stable astaxanthin-rich formulations from Haematococcus pluvialis. Food Chem 279: 294-302, 2019.

66. Lin SF, Chen YC, Chen RN, Chen LC, Ho HO, Tsung YH, Sheu MT and Liu DZ: Improving the stability of astaxanthin by microencapsulation in calcium alginate beads. PLoS One 11: e0153685, 2016.

67. Niizawa I, Espinaco BY, Zorrilla SE and Sihufe GA: Natural astaxanthin encapsulation: Use of response surface methodology for the design of alginate beads. Int J Biol Macromol 121: 601-608, 2019

68. Hama S, Uenishi S, Yamada A, Ohgita T, Tsuchiya H, Yamashita $\mathrm{E}$ and Kogure K: Scavenging of hydroxyl radicals in aqueous solution by astaxanthin encapsulated in liposomes. Biol Pharm Bull 35: 2238-2242, 2012.

69. Chiu CH, Chang CC, Lin ST, Chyau CC and Peng RY: Improved hepatoprotective effect of liposome-encapsulated astaxanthin in lipopolysaccharide-induced acute hepatotoxicity. Int J Mol Sci 17: E1128, 2016.

70. Wu YC, Huang HH, Wu YJ, Manousakas I, Yang CC and Kuo SM: Therapeutic and protective effects of liposomal encapsulation of astaxanthin in mice with alcoholic liver fibrosis. Int J Mol Sci 20: E4057, 2019

71. Anarjan N, Tan CP, Nehdi IA and Ling TC: Colloidal astaxanthin: Preparation, characterisation and bioavailability evaluation. Food Chem 135: 1303-1309, 2012.

72. Yang Y, Kim B and Lee JY: Astaxanthin structure, metabolism, and health benefits. J Hum Nutr Food Sci 1: 1003, 2013.

73. Kamezaki C, Nakashima A, Yamada A, Uenishi S, Ishibashi H, Shibuya N, Hama S, Hosoi S, Yamashita E and Kogure K: Synergistic antioxidative effect of astaxanthin and tocotrienol by co-encapsulated in liposomes. J Clin Biochem Nutr 59: 100-106, 2016.

74. Ishikawa M, Hirai S, Yoshida T, Shibuya N, Hama S, Takahashi Y, Fukuta T, Tanaka T, Hosoi S and Kogure K: Carotenoid stereochemistry affects antioxidative activity of liposomes co-encapsulating astaxanthin and tocotrienol. Chem Pharm Bull (Tokyo) 66: 714-720, 2018.

75. Kittikaiwan P, Powthongsook S, Pavasant P and Shotipruk A: Encapsulation of Haematococcus pluvialis using chitosan for astaxanthin stability enhancement. Carbohydr Polym 70: 378-385, 2007.

76. Wang Q, Zhao Y, Guan L, Zhang Y, Dang Q, Dong P, Li J and Liang X: Preparation of astaxanthin-loaded DNA/chitosan nanoparticles for improved cellular uptake and antioxidation capability. Food Chem 227: 9-15, 2017.

77. Liu C, Liu Z, Sun X, Zhang S, Wang S, Feng F, Wang D and Xu Y: Fabrication and characterization of $\beta$-lactoglobulin-based nanocomplexes composed of chitosan oligosaccharides as vehicles for delivery of astaxanthin. J Agric Food Chem 66: 6717-6726, 2018. 
78. Chereddy KK, Vandermeulen G and Préat V: PLGA based drug delivery systems: Promising carriers for wound healing activity. Wound Repair Regen 24: 223-236, 2016.

79. Zhang $\mathrm{J}$ and Peng CA: Enhanced proliferation and differentiation of mesenchymal stem cells by astaxanthin-encapsulated polymeric micelles. PLoS One 14: e0216755, 2019.

80. Dias V, Junn E and Mouradian MM: The role of oxidative stress in Parkinson's disease. J Parkinsons Dis 3: 461-491, 2013.

81. Kim SH and Kim H: Inhibitory effect of astaxanthin on oxidative stress-induced mitochondrial dysfunction-A mini-review. Nutrients 10: E1137, 2018.

82. Starkov AA: The role of mitochondria in reactive oxygen species metabolism and signaling. Ann NY Acad Sci 1147: 37-52, 2008.

83. Siemen D and Ziemer M: What is the nature of the mitochondrial permeability transition pore and what is it not? IUBMB Life 65: 255-262, 2013.

84. Valenti MT, Garbin U, Pasini A, Zanatta M, Stranieri C, Manfro S, Zucal C and Dalle Carbonare L: Role of ox-PAPCs in the differentiation of mesenchymal stem cells (MSCs) and Runx 2 and PPAR $\gamma 2$ expression in MSCs-like of osteoporotic patients. PLoS One 6: e20363, 2011.

85. Sobenin IA, Sazonova MA, Postnov AY, Bobryshev YV and Orekhov AN: Mitochondrial mutations are associated with atherosclerotic lesions in the human aorta. Clin Dev Immunol 2012: 832464, 2012.

86. Kluge MA, Fetterman JL and Vita JA: Mitochondria and endothelial function. Circ Res 112: 1171-1188, 2013.

87. Apostolova $\mathrm{N}$ and Victor VM: Molecular strategies for targeting antioxidants to mitochondria: Therapeutic implications. Antioxid Redox Signal 22: 686-729, 2015.

88. Wolf AM, Asoh S, Hiranuma H, Ohsawa I, Iio K, Satou A Ishikura $M$ and Ohta $S$ : Astaxanthin protects mitochondrial redox state and functional integrity against oxidative stress. J Nutr Biochem 21: 381-389, 2010

89. Park JS, Mathison BD, Hayek MG, Zhang J, Reinhart GA and Chew BP: Astaxanthin modulates age-associated mitochondrial dysfunction in healthy dogs. J Anim Sci 91: 268-275, 2013.

90. Song X, Wang B, Lin S, Jing L, Mao C, Xu P, Lv C, Liu W and Zuo J: Astaxanthin inhibits apoptosis in alveolar epithelial cells type II in vivo and in vitro through the ROS-dependent mitochondrial signalling pathway. J Cell Mol Med 18: 2198-2212, 2014

91. Fan CD, Sun JY, Fu XT, Hou YJ, Li Y, Yang MF, Fu XY and Sun BL: Astaxanthin attenuates homocysteine-induced cardiotoxicity in vitro and in vivo by inhibiting mitochondrial dysfunction and oxidative damage. Front Physiol 8: 1041, 2017.

92. Reid MB, Shoji T, Moody MR and Entman ML: Reactive oxygen in skeletal muscle. II. Extracellular release of free radicals. J Appl Physiol (1985) 73: 1805-1809, 1992.

93. Aoi W, Naito Y, Sakuma K, Kuchide M, Tokuda H, Maoka T, Toyokuni S, Oka S, Yasuhara M and Yoshikawa T: Astaxanthin limits exercise-induced skeletal and cardiac muscle damage in mice. Antioxid Redox Signal 5: 139-144, 2003.
94. McGarry JD and Brown NF: The mitochondrial carnitine palmitoyltransferase system. From concept to molecular analysis. Eur J Biochem 244: 1-14, 1997.

95.Ikeuchi M, Koyama T, Takahashi J and Yazawa K: Effects of astaxanthin supplementation on exercise-induced fatigue in mice. Biol Pharm Bull 29: 2106-2110, 2006.

96. Belviranli M, Okudan N and Lamprecht M (eds): Well-Known Antioxidants and Newcomers in Sport Nutrition: Coenzyme Q10. Quercetin, Resveratrol, Pterostilbene, Pycnogenol and Astaxanthin.In: Antioxidants in Sport Nutrition. CRCPress/Taylor and Francis, Boca Raton, FL, 2015.

97. Yaghooti H, Mohammadtaghvaei $\mathrm{N}$ and Mahboobnia K: Effects of palmitate and astaxanthin on cell viability and proinflammatory characteristics of mesenchymal stem cells. Int Immunopharmacol 68: 164-170, 2019.

98. Domazetovic V, Marcucci G, Pierucci F, Bruno G, Di Cesare Mannelli L, Ghelardini C, Brandi ML, Iantomasi T, Meacci E and Vincenzini MT: Blueberry juice protects osteocytes and bone precursor cells against oxidative stress partly through SIRT1. FEBS Open Bio 9: 1082-1096, 2019.

99. Balci Yuce H, Lektemur Alpan A, Gevrek F and Toker H: Investigation of the effect of astaxanthin on alveolar bone loss in experimental periodontitis. J Periodontal Res 53: 131-138, 2018.

100. Hwang YH, Kim KJ, Kim SJ, Mun SK, Hong SG, Son YJ and Yee ST: Suppression effect of astaxanthin on osteoclast formation in vitro and bone loss in vivo. Int J Mol Sci 19: E912, 2018.

101.El-Baz FK, Saleh DO, Abdel Jaleel GA, Hussein RA and Hassan A: Heamatococcus pluvialis ameliorates bone loss in experimentally-induced osteoporosis in rats via the regulation of OPG/RANKL pathway. Biomed Pharmacother 116: 109017, 2019.

102. Valenti MT, Dalle Carbonare L and Mottes M: Osteogenic Differentiation in Healthy and Pathological Conditions. Int J Mol Sci 18: 41, 2016.

103. Kimble L, Mathison B and Chew BP: Astaxanthin mediates inflammatory biomarkers associated with arthritis in human chondrosarcoma cells induced with interleukin-1 beta. FASEB J 27 (Suppl 1): 638, 2013

104. Chen WP, Xiong Y, Shi YX, Hu PF, Bao JP and Wu LD Astaxanthin reduces matrix metalloproteinase expression in human chondrocytes. Int Immunopharmacol 19: 174-177, 2014.

105.Huang LJ and Chen WP: Astaxanthin ameliorates cartilage damage in experimental osteoarthritis. Mod Rheumatol 25 768-771, 2015.

106. Booth FW, Roberts CK and Laye MJ: Lack of exercise is a major cause of chronic diseases. Compr Physiol 2: 1143-1211, 2012. 